\title{
Thermal, mechanical and environmental degradation characteristics of polyhydroxybutyrate-co-valerate reinforced with cellulose fibers
}

\begin{abstract}
The development of biodegradable polymers has advanced in recent years, mainly due to the overwhelming need to reduce the impact of polymeric materials when improperly discarded in nature. However, there are major challenges to be surpassed, especially regarding characteristics such as mechanical strength and cost of such materials, when compared to commodity polymers widely used today. Motivated by this goal, this study focused on the development of a composite material consisting of a biodegradable polymer the poly(hydroxybutyrate-co-valerate) (PHBV) reinforced with cellulose fibers, which are cheap and abundant. Mechanical and thermal properties of the polymer reinforced with different fiber contents were analyzed and compared with the neat material. Also, a burialsoil test was carried out to evaluate the environmentally degradable characteristics of the compositions studied. Results showed that the incorporation of cellulose fibers into the biodegradable matrix can both optimize the mechanical properties in use, and accelerating the environmental degradation of the polymeric material after use, when properly disposed, showing that biodegradable composites are environmentally friendly.
\end{abstract}

Volume 5 Issue I - 202I

\author{
Tiago Cristofer Aguzzoli Colombo,' Ana \\ Maria Coulon Grisa, ${ }^{1,2}$ Ademir José Zattera, ${ }^{2}$ \\ Rosmary Nichele Brandalise ${ }^{2}$ \\ 'Federal Institute of Education, Science and Engineering (IFRS), \\ Brazil \\ ${ }^{2}$ Graduate Program in Process and Technology Engineering \\ (PGPROTEC), University of Caxias do Sul (UCS), Brazil
}

Correspondence: Ana Maria Coulon Grisa, Graduate Program in Process and Technology Engineering (PGPROTEC), University of Caxias do Sul,Tel (054)999452360,Email amcgris@ucs.br

Received: January 04, 202I | Published: February II, 202 I

Keywords: PHBV, cellulose fibers, mechanical properties, biodegradation.

\section{Introduction}

Poly(hydroxybutyrate-co-hydroxyvalerate) (PHBV) is a biodegradable copolyester consisting of hydroxybutyrate (HB) and hydroxyvalerate (HV). PHBV belongs to the family of polyhydroxyalkanoates (PHA), synthesized by a wide variety of bacteria as an intracellular reserve of carbon and energy. ${ }^{1,2}$ PHBV has gained a lot of attention in the recent years as an eco-friendly material, produced by renewable sources, biodegradable and biocompatible polymer, and can be processed by usual techniques applied to common polymers. ${ }^{3}$ The similarity of some properties to the polypropylene (PP) indicates that it may be a future substitute for the polyolefins, finding application in products with short life cycle, including toys, shavers, agricultural and cosmetic packaging, napkins, cups and plastic cutlery. PHBV has been also used in the medical field in bone grafts, soft gels, pins, sutures and in neural tissue engineering due to its biocompatibility., The use of polymers with biodegradable characteristics, such as PHBV, mixed with natural fibers, which also have biodegradable characteristics and are abundant in nature, may have the potential to produce materials with desirable mechanical characteristics, inexpensive, and at the same time environmentally friendly as it can degrade spontaneously when disposed in nature. However, it is necessary to understand how biodegradable polymers and natural fibers interact with each other, focusing on determining the mixing conditions that provide optimal performance conditions for use of the material and improved biodegradation characteristics after discarded. The present study describes the influence of untreated cellulose fibers in the PHBV matrix on the thermal, mechanical and biodegradation properties of the resulting composite. The biodegradation properties were evaluated by soil-burial test according to standard ASTM G160.

\section{Experimental}

\section{Materials}

Materials used for this study were: poly(hydroxybutyrate-cohydroxyvalerate) (PHBV) containing $3.34 \mathrm{~mol} \%$ of hydroxyvalerate, supplied by PHB Industrial S.A. (Serrana, Brazil) and cellulose fibers from the pine PinusTaeda, supplied by Cambará S.A. (Cambará do Sul, Brazil).

\section{Preparation of composites PHBV and cellulose fibers}

Composites containing $20 \mathrm{wt} \%$ and $40 \mathrm{wt} \%$ of cellulose fibers were prepared. The PHBV and cellulose fibers were dried in an oven with air circulation at $70^{\circ} \mathrm{C}$ for a period of 72 hours. After drying, the composites were prepared by a molten mixture process in a corotating twin screw extruder with five heating zones and the following temperature profile: $150 / 155 / 160 / 170 / 165^{\circ} \mathrm{C}$ (barrel to matrix, respectively) and 200rpm rotation. The compositions used in the composites and neat PHVB are shown in Table 1. After processing in the extruder, the mix was transferred to a preheated injection molding machine for specimen fabrication. Specimens, with dimensions $127 \times 12.7 \times 3.2 \mathrm{~mm}$, according to ASTM D790 for flexural testing, were molded at temperature of $160^{\circ} \mathrm{C}$ and the injection pressure was 655 bar. The injection tool was kept at $6^{\circ} \mathrm{C}$.

\section{Burial-soil test}

The environmental degradation test for PHBV and composites was carried out using a burial-soil test, according to ASTM G160. The detailed composition was as follows: $5 \mathrm{~kg}$ of coarse sand (10 mesh), $5 \mathrm{~kg}$ of fertile topsoil and $5 \mathrm{~kg}$ of well-rotted horse manure. The soil composition was prepared by simple mixing and sifted through $1 / 4$ in. mesh screen. After mixing, the mixture was aged for three months. At 
the end of the aging time, the mixture was divided into sixty $500 \mathrm{ml}$ polypropylene cups, and each cup received one specimen. There were three exposure times for each composition: 30, 60 and 90 days.

Table I Compositions used in the composites of PHVB and neat PHVB

\begin{tabular}{lll}
\hline Composition & PHBV (wt. \%) & Cellulose fibers (wt. \%) \\
\hline PHBV & 100 & 0 \\
PHBV/ CF 80/20 & 80 & 20 \\
PHBV/ CF 60/40 & 60 & 40 \\
\hline
\end{tabular}

\section{Methods of characterization}

Fourier transformed infrared spectroscopy (FTIR): FTIR analysis was performed using a model Nicolet iS10 spectrometer from Thermo Scientific. FTIR analysis were performed for all the compositions, before and after the burial-soil test, to investigate changes related to the chemical composition of the samples, as when incorporating cellulose fibers as during the burial-soil test. Each sample was milled in a cryogenic mill, cold with liquid nitrogen, for a period of 5 minutes. After milling, the powder obtained was mixed with $\mathrm{KBr}$ and made into a pellet, and then it was fixed to the FTIR sample plate. Spectra were taken in triplicate for each sample at 400 to $4000 \mathrm{~cm}^{-1}$.

Differential scanning calorimetry (DSC): DSC of the samples was performed using a model DSC-50 from Shimadzu Corporation. The same heat/cool method was adopted for all specimens testing, before and after burial soil test. Specimens were heated from $0^{\circ} \mathrm{C}$ to $200^{\circ} \mathrm{C}$, at a ramp hate of $10^{\circ} \mathrm{C} \cdot \mathrm{min}^{-1}$ and cooled with the same ramp. The data for melting points and enthalpy of fusion were recorded during the heating cycle. The crystallinities of neat PHBV and PHBV in the composites were obtained from the following equations:

$$
X c_{1}=\left(\Delta H_{f} / \Delta H_{o}\right) \times 100
$$

$$
X c_{2}=\left(\Delta H_{f} /\left(\Delta H_{o} \times W\right)\right) \times 100
$$

where $\mathrm{Xc}_{1}$ and $\mathrm{Xc}_{2}$ are the crystallinities of the neat PHBV and PHBV in the composites, respectively, $\Delta \mathrm{H}_{\mathrm{o}}$ is the thermodynamic enthalpy of fusion per gram of PHBV $\left(109{\mathrm{~J} . \mathrm{g}^{-1}}^{-1}\right), \Delta \mathrm{H}_{\mathrm{f}}$ is the apparent enthalpy of fusion per gram of PHBV/Cellulose fiber composites and $\mathrm{W}$ is the fraction of mass content of PHBV in the composites (Sing et al., 2010). ${ }^{5}$

Thermogravimetric analysis (TGA): TGA of the samples was performed using a model TGA-50 from Shimadzu Corporation. The samples were heated from room temperature to $700^{\circ} \mathrm{C}$, with a heating rate of $20{ }^{\circ} \mathrm{C} \cdot \mathrm{min}^{-1}$, using nitrogen atmosphere.

Mechanical behavior: Flexural properties of the neat PHBV and composites were performed using an EMIC DI-3000 testing machine, according to ASTM D790.The samples were evaluated before and after soil-burial tests. The numbers of samples tested in each case were five for all the respective compositions.

Scanning electron microscopy (SEM): The surface morphology of the neat PHBV samples before and after soil-burial tests was investigated by scanning electron microscopy (Superscan S-550,
Shimadzu, Japan), to check for structural changes during the burialsoil period. The samples were mounted on aluminum stubs and then coated with carbon in vacuum by evaporation in order to make the samples conducting.

\section{Results and discussions}

\section{Before burial-soil test}

FTIR: Figure 1 illustrates FTIR spectra for PHBV, cellullose fibers and the composites. Analyzing Figure 1 it was possible to note that FTIR spectra for the composites are a combination from the PHBV and cellullose fibers spectras. When increasing the cellullose fibers content, there is a change in the region between 3700 to $3000 \mathrm{~cm}^{-1}$. The shape of the band stays the same with its center around $3200 \mathrm{~cm}^{-1}$, but there is an increasing at the area above the band when increasing the fiber content. This region at the FTIR spectra is related to hydroxyl stretching, possibly indicating hydrogen bonds between the hydroxyls belonging to cellulose fibers and the carbonyls belonging to PHBV. The band at $3437 \mathrm{~cm}^{-1}$ from the PHBV spectra can be related to water content from $\mathrm{KBr}$ used in the specimens as well an overtone from carbonyl band at $1720 \mathrm{~cm}^{-1}$.

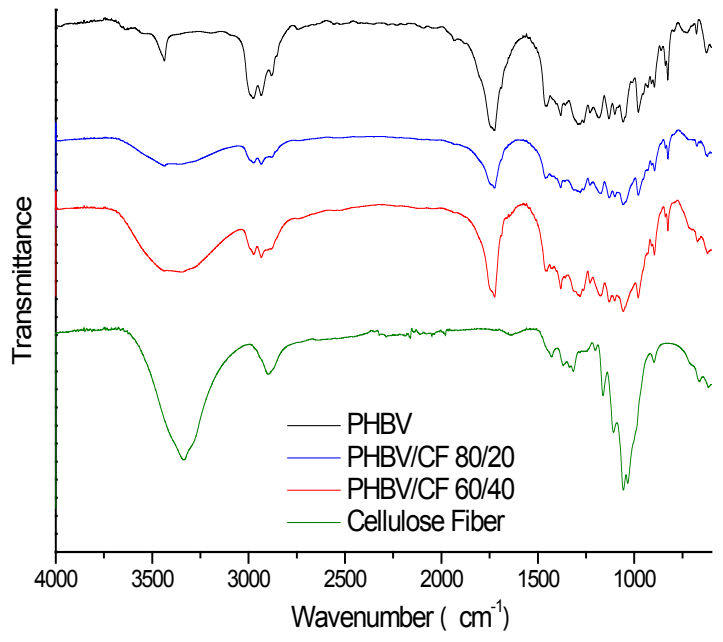

Figure I FTIR spectra for neat PHBV, cellulose fibers and composites PHBV/ CF.

DSC: Figure 2 illustrates DSC melting curves of neat PHBV and composites. The details are given in Table 2. Adding cellulose fibers in the PHBV matrix did not affect its melting point which remains at $161^{\circ} \mathrm{C}$ for both compositions. As shows Table 2, the addition of cellulose fibers increased the crystallinity of PHBV. This behavior indicates that the cellulose fiber facilitates the crystallization of PHBV, which can be correlated with the easier processing and higher dimensional stability of the composites specimens if compared to neat PHBV. Neat PHBV showed no crystallization peak during cooling, Figure 3, and showed a peak in the second heating. This behavior indicates that the polymer has slow crystallization kinetics, not crystallizing for the cooling rate used in the analysis. However, when adding cellulose fibers in the polymer matrix, it showed crystallization peak during cooling, reinforcing the idea that cellulose fibers facilitate the crystallization of PHBV. Figure 3 illustrates crystallization peaks for neat PHBV and composites at the cooling stage. The maximum temperature of crystallization occurs at $67^{\circ} \mathrm{C}$ and $71^{\circ} \mathrm{C}$, for $20 \mathrm{wt} . \%$ and $40 \mathrm{wt} . \%$ of cellulose fiber in the composites, respectively. 


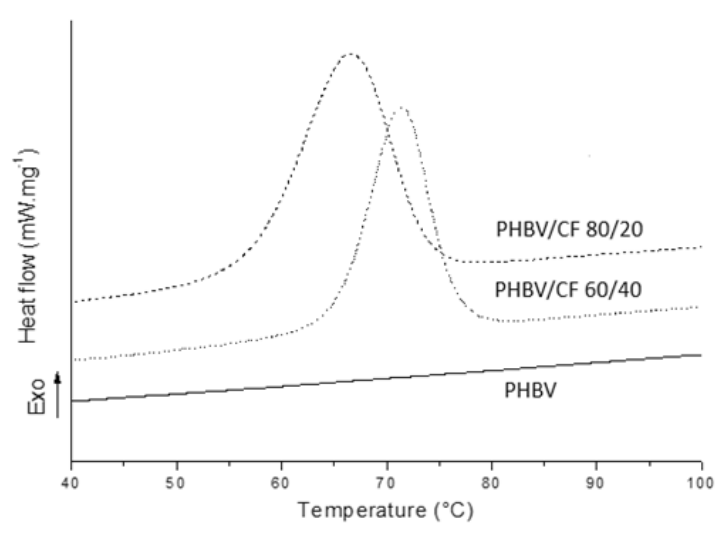

Figure 2 Melting curves for neat PHBV and composites PHBV/CF.

Table 2 Enthalpy of fusion and crystallinities of neat PHBV and composites

\begin{tabular}{lll}
\hline Composition & $\Delta \mathbf{H}_{\mathrm{f}}(\mathbf{J} / \mathbf{g})$ & $\mathbf{X}_{\mathrm{c}}(\%)$ \\
\hline PHBV & 36.19 & 33.2 \\
PHBV/ CF 80/20 & 39.93 & 45.79 \\
PHBV/ CF 60/40 & 35.07 & 53.62 \\
\hline
\end{tabular}

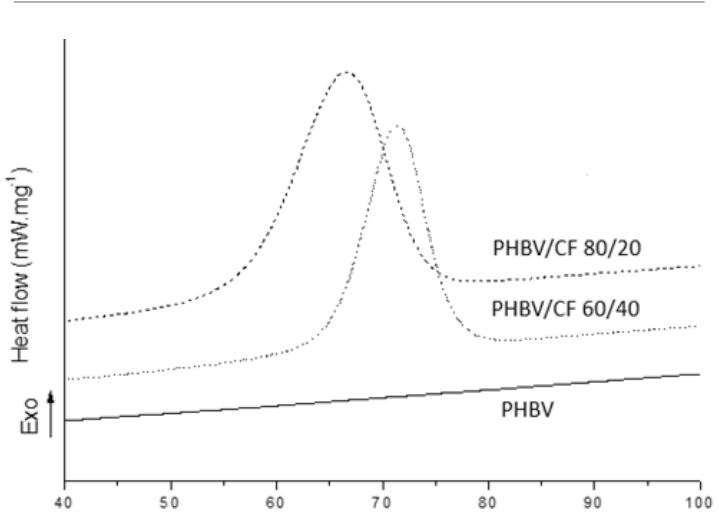

Figure 3 Crystallization curves of PHBV and composites PHBV/CF.

TGA: Figure 4 illustrates the weight loss curves of neat PHBV, composites and cellulose fibers. PHBV begins to thermally degrade at $260^{\circ} \mathrm{C}$ and degrades completely at $350^{\circ} \mathrm{C}$, reaching the maximum degradation at $310^{\circ} \mathrm{C}$. Cellulose fibers have a first weight loss from $40^{\circ} \mathrm{C}$ to $120^{\circ} \mathrm{C}$, related to water loss, and a second weight loss related to thermal degradation, beginning at $250^{\circ} \mathrm{Cuntil}$ around $400^{\circ} \mathrm{C}$, reaching the maximum degradation at $360^{\circ} \mathrm{C}$. The PHBV lost weight gradually with the increasing temperature. The PHBV degradation process involves chain scission and hydrolysis which leads to reduction in molecular weight and formation of crotonic acid (Singh et al., 2008). As illustrates Figure 4, the thermal degradation behavior of composites is a cumulative phenomenon of thermal degradation of neat PHBV and cellulose fiber. Degradation of both composites starts at $260^{\circ} \mathrm{C}$ and ends at $390^{\circ} \mathrm{C}$. The TGA of composites also showed the fibers to be the final constituent to undergo degradation in composites. Figure 5 illustrates the derivative weight loss of PHBV and composites. It is noted that the addition of $40 \mathrm{wt} \%$ cellulose fiber gently moves the peak of the TGA curve to the left, indicating that the addition of cellulose content decreases slightly the thermal stability of PHBV, and this behavior may be due to degradation of hydroxyl groups in cellulose. ${ }^{5}$ Table 3 shows thermal events and corresponding temperatures observed through the TGA curves.

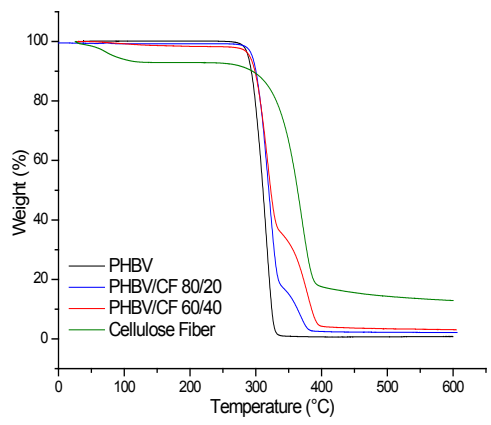

Figure 4 Weight loss of PHBV, cellulose fiber and their composites.

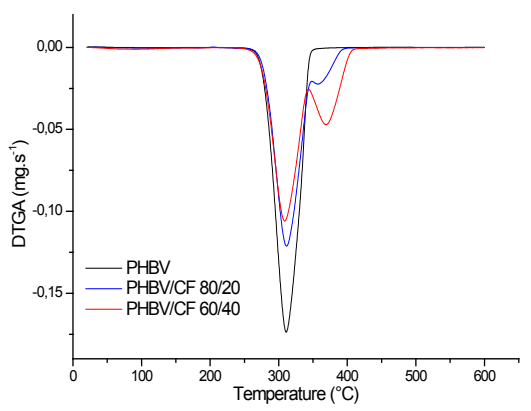

Figure 5 Derivative weight loss of PHBV and composites PHBV/CF.

Table 3 Thermal events and corresponding temperatures observed for of $\mathrm{PHBV}$ and composites PHBV/CF

\begin{tabular}{|c|c|c|c|}
\hline Composition & Tonset $\left({ }^{\circ} \mathrm{C}\right)$ & Tendset $\left({ }^{\circ} \mathrm{C}\right)$ & Related to \\
\hline Cellulose fibers & 40 & 120 & water loss \\
\hline Cellulose fibers & 250 & 400 & $\begin{array}{l}\text { thermal } \\
\text { degradation }\end{array}$ \\
\hline PHBV & 260 & 350 & $\begin{array}{l}\text { thermal } \\
\text { degradation }\end{array}$ \\
\hline $\mathrm{PHBV} / \mathrm{CF} 80 / 20$ & 250 & 355 & $\begin{array}{l}\text { thermal } \\
\text { degradation of } \\
\text { PHBV + CF }\end{array}$ \\
\hline $\mathrm{PHBV} / \mathrm{CF} 80 / 20$ & 350 & 400 & $\begin{array}{l}\text { thermal } \\
\text { degradation of } \\
\mathrm{CF}\end{array}$ \\
\hline $\mathrm{PHBV} / \mathrm{CF} 60 / 40$ & 245 & 345 & $\begin{array}{l}\text { thermal } \\
\text { degradation of } \\
\text { PHBV + CF }\end{array}$ \\
\hline $\mathrm{PHBV} / \mathrm{CF} 60 / 40$ & 345 & 410 & $\begin{array}{l}\text { thermal } \\
\text { degradation of } \\
\mathrm{CF}\end{array}$ \\
\hline
\end{tabular}

Mechanical behavior: Table 4 presents the average results of maximum flexural strength, elongation at the break and Young's modulus for the neat PHBV and composites. It is noted that with the 
addition of cellulose fiber to the polymer matrix, the material stiffness becomes higher. The addition of 20 wt. $\%$ and 40 wt. \%of cellulose fibers did not affect the flexural strength, considering the standard deviations. Uniaxial orientation of the reinforcement fibers in the polymer matrix can provide better results for tensile strength, than for flexural strength as evidenced in this study to one random orientation of fibers. For flexural strength, the strength of the reinforcement is one of the most important aspects. ${ }^{4,6}$ The elongation at the break also was not modified when adding $20 \mathrm{wt} . \%$ cellulose fibers, whereas with the addition of $40 \mathrm{wt} . \%$ cellulose fibers, the elongation at the break decreased by about $54 \%$. At $20 \mathrm{wt} \%$ of fiber content the Young's modulus increased about $55 \%$ and increased notable $118 \%$ at 40 $w t \%$ of fiber content. In flexural tests, tension is more localized in the region where the force is applied, unlike what occurs in a tensile test, where tension is distributed throughout the specimens and also is more sensitive to the defects originated through the interfaces between matrix and fibers. Dipolar groups on cellulose (hydroxyl groups) and on PHBV (carbonyl group) can provide a better interfacial interaction between phases. ${ }^{7}$ The increasing in Young's modulus with the addition of cellulose fibers indicates that there is a reasonable interfacial interaction between PHBV and fibers, which allows the tension applied on the matrix be redistributed to reinforcement phase, the cellulose fibers. This behavior improves the stiffness of the material, which could be observed during the processing of the specimens.

Table 4 Flexural strength, elongation at the break and Young's modulus of PHBV and composites

\begin{tabular}{llll}
\hline Composition & $\begin{array}{l}\text { Flexural } \\
\text { strength } \\
(\mathbf{M P a})\end{array}$ & $\begin{array}{l}\text { Elongation at the } \\
\text { break (\%) }\end{array}$ & $\begin{array}{l}\text { Young's } \\
\text { Modulus } \\
(\mathbf{G P a})\end{array}$ \\
\hline PHBV & $27.0 \pm 1.0$ & $4.1 \pm 0.3$ & $1.27 \pm 0.13$ \\
PHBV/CF 80/20 & $27.0 \pm 2.0$ & $4.1 \pm 0.3$ & $1.97 \pm 0 \mathrm{~A} 7$ \\
$\mathrm{PHBV} / \mathrm{CF} 60 / 40$ & $29 \pm 2.2$ & $1.9 \pm 0.3$ & $2.77 \pm 0.34$ \\
\hline
\end{tabular}

FTIR for neat PHBV and composites after burial-soil test: Figure 6 illustrates FTIR spectra for PHBV before and after burial-soil tests. From Figure 6 it is possible to note that the characteristic bands for PHBV did not change significantly. There is a small stretching of the band around $3437 \mathrm{~cm}^{-1}$, what can be related to the increasing in water content in the samples, possibly from the environment where the samples were exposed as well as an indication of hydrolysis process inside the polymeric material. Analyzing the region between 3700 and $3000 \mathrm{~cm}^{-1}$ for both composites, it is possible to observe that the samples exposed to burial-soil test showed an enlargement in relation to the samples not exposed to the same test. This enlargement is much clearer in the composites spectra than in the neat PHBV spectra. This region is related to the $\mathrm{OH}$ stretching vibration, and this behavior may be indicative of hydrolysis of PHBV was also observed in the studies of Zhijiang et al. ${ }^{8}$ The degradation of the fibres occurs by of the interaction of cellulose fibers with wate, where the loss of adhesion between fibre and matrix, characterized by the apparition of voids. The fibres degrade with complete lack of pectin layer and the water interact with the surface of the constituting fibrils that involved the hydroxyl groups residing on the no crystalline surface of the fibrils ${ }^{4,9}$

Figure 7 \& Figure 8 illustrate FTIR spectra for composites PHBV/ FC $80 / 20$ and 60/40 respectively. Possibly physical disintegration observed in samples can be facilitating both access of microorganisms into the polymer matrix and the diffusion of water, enhancing the process of hydrolysis and material degradation. Moreover, Figure 8 illustrates the appearance of a band in the region around $1650 \mathrm{~cm}^{-1}$ (indicated by arrows). This region of transmittance is indicative of amide I, which may result from proteins produced by microorganisms. However, this same region, along with a slight increase in intensity observed near $1425 \mathrm{~cm}^{-1}$ corresponds to the carboxylate anion. ${ }^{10} \mathrm{No}$ significant change was observed on the carbonyl band at $1720 \mathrm{~cm}^{-1}$. Analyzing Figure $7 \&$ Figure 8 it is possible to observe an increase in transmittance in the band at about $1050 \mathrm{~cm}^{-1}$. This band can be related to the primary alcohol, which its characteristic bands are between 1085 to $1050 \mathrm{~cm}^{-1}$

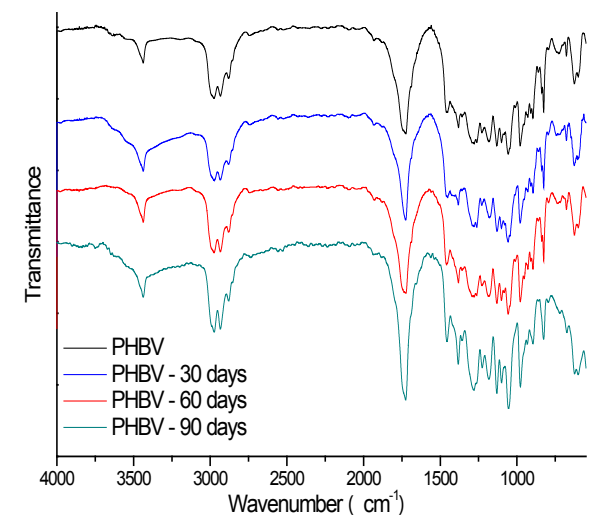

Figure 6 FTIR spectra for neat PHBV before and after burial-soil test.

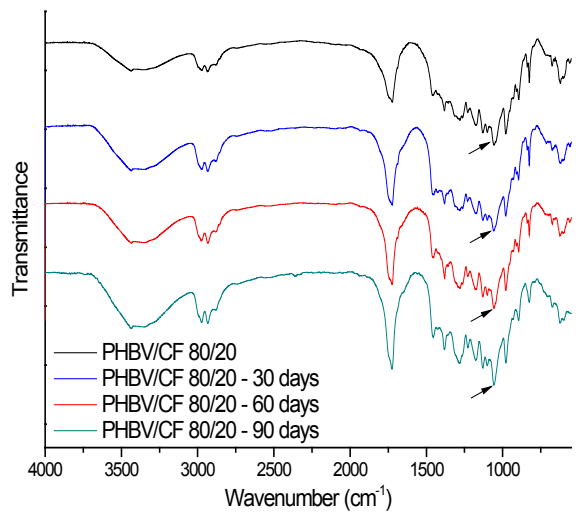

Figure 7 FTIR spectra for PHBV/FC 80/20 before and after burial-soil test.

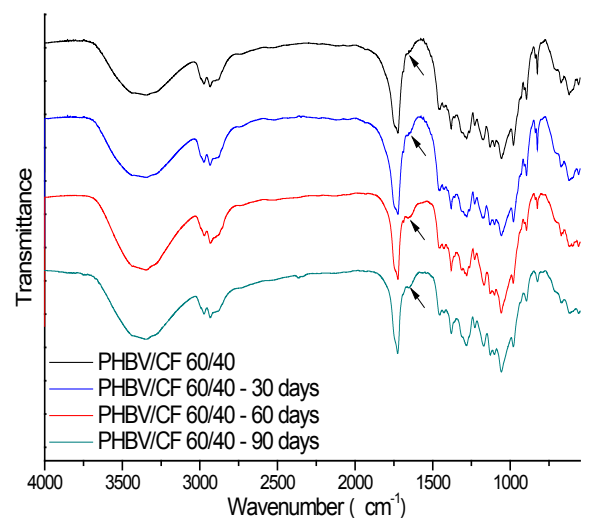

Figure 8 FTIR spectra for PHBV/FC 60/40 before and after burial-soil test. 
Differential scanning calorimetry (DSC) for neat PHBV and composites after burial-soil test: Table 5 show the thermal characteristics and crystallinity for neat PHBV and composites before and after burial-soil test. Table 5 shows that there were no major changes in both melting point and crystallinity of the neat PHBV, comparing the different exposure times to burial-soil test. However, it is possible to observe a slight decrease in crystallinity with 90 days of exposure to burial-soil test. According to Table 5 for PHVB/ $\mathrm{CF} / 80 / 20 \mathrm{PHVB} / \mathrm{CF} / 60 / 420$, composites showed a large decrease in crystallinity of the polymer with increasing exposure time to burialsoil test. The degree of crystallinity can be defined as an index which evaluates the microstructural ordering of atomic or molecular groups present in polymers. The degree of crystallinity is directly related to the composition of material, chemical structure, molecular weight and processing conditions in which the material is submitted. In general, as higher is the crystallinity, as greater is the resistance of the material to hydrolysis and oxidation. ${ }^{4,11,12}$ Amorphous polymers with lower chain packing tend to present higher rates of degradation. In the case of PHBV, in which the crystalline phase corresponds to the hydroxybutyrate (HB) and amorphous phase corresponding to hidroxivalerato (HV), it leads to deduce that the degradation process occurs preferentially in the amorphous phase, increasing material crystallinity. For exposure times of up to 60 days, this behavior was not observed. In composites, cellulose can absorb soil moisture and swell. In this way, the reinforcemegoogle tradutornt can make the polymer matrix more susceptible to microorganisms. The loss of physical integrity of the composite, PHBV becomes susceptible to degradation for hydrolysis, causing chain scission and loss of molecular weight, leading to a decrease in crystallinity. For samples exposed for 90 days to the burial-soil test, an increase of crystallinity was observed, which may be related to a more severe degradation of the amorphous phase in the PHVB ${ }^{10}$ and de cellulose fibers. The results with 90 days of exposure are similar to those of neat PHBV.

Table 5 Thermal characteristics and crystallinity for neat PHBV, PHBV/CF $80 / 20$ and $\mathrm{PHBV} / \mathrm{CF} 60 / 40$

\begin{tabular}{lll}
\hline PHBV & & \\
\hline Exposition time & $\Delta \mathbf{H}_{\mathrm{f}}(\mathrm{J} / \mathbf{g})$ & $\mathbf{X}_{\mathrm{c}}(\%)$ \\
Before exposition & 36.2 & 33.2 \\
30 days & 38.6 & 35.1 \\
60 days & 33.6 & 30.5 \\
90 days & 30.3 & 27.8 \\
PHBV/CF 80/20 & & \\
Exposition time & $\Delta \mathbf{H}_{\mathrm{f}}(\mathrm{J} / \mathrm{g})$ & $\mathbf{X}_{\mathrm{c}}(\%)$ \\
Before exposition & 35.0 & 40.1 \\
30 days & 28.1 & 32.2 \\
60 days & 17.6 & 20.2 \\
90 days & 24.7 & 28.3 \\
PBBV/CF 60/40 & & \\
Exposition time & $\Delta \mathbf{H}_{\mathrm{f}}(\mathrm{J} / \mathbf{g})$ & $\mathbf{X}_{\mathrm{c}}(\%)$ \\
Before exposition & 35.1 & 53.6 \\
30 days & 21.9 & 33.5 \\
60 days & 12.3 & 18.8 \\
90 days & 16.5 & 25.2 \\
\hline
\end{tabular}

TGA for neat PHBV and composites after burial-soil test: Figure 9 illustrates the derivative thermogravimetric curves of PHBV and composites before and after burial-soil test. It was observed that there is a gentle shift of thermogravimetric curves. Samples exposed to burial-soil test had their beginning of mass loss at lower temperatures compared to the samples that was not exposed to burial-soil test, indicating a possible structural modification of the polymer chains. The same behavior can be observed for the temperatures at the end of mass loss and temperatures which the maximum mass loss rate occurs. The lower the onset temperature for mass loss, the lower the thermal stability of the sample to the conditions of the experiment, i.e., the polymer molecules require less energy to break the intermolecular bonds. Results for neat PHBV indicate loss of thermal stability for samples exposed to burial-soil test, and this loss was more pronounced for the sample exposed for 60 days to the test. The same behavior of neat PHBV was observed for both composites. For the samples exposed to burial-soil test, mass loss starts and ends at lower temperatures, comparing to samples not exposed to burial-soil test. The same behavior can be observed for the temperatures which maximum mass loss rate occurs, decreasing for samples exposed to burial-soil test. These results indicate that, as for neat PHBV, the exposure to burial-soil test leads to structural changes in materials, leading to loss of thermal stability for both composites. This behavior is confirmed by the presented results of loss of crystallinity.

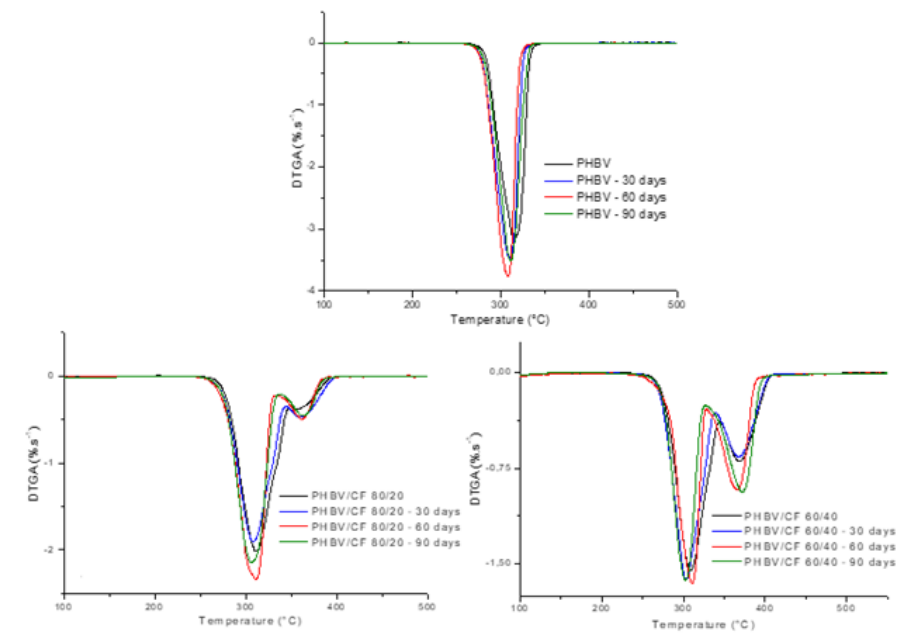

Figure 9 TGA curves for PHVB and composites before and after burial-soil test.

Mechanical behaviour for neat PHBV and composites after burial-soil test: Results show a loss of mechanical properties for all samples after burial-soil test (Table 6). After 30 days of exposure to burial-soil test, PHBV practically did not show changes in flexural strength, but showed a decrease of around 3.5\% in Young's modulus. On the other hand, composite PHBV/FC 80/20 showed a decrease in flexural strength of around $22 \%$ and a decrease in Young's modulus of around 13\%. PHBV/FC 60/40 showed the highest decrease in mechanical properties after 30 days of exposure to burial-soil test. Flexural strength decreased around $64 \%$ and Young's modulus decreased around $45 \%$ comparing to the values before the burialsoil test. After 60 days of exposure to burial-soil test all the samples showed decrease in mechanical properties. For neat PHBV flexural strength decreased $10 \%$ and Young's modulus decreased around $6 \%$. For PHBV/FC 80/20, flexural strength decreased around 51\% and Young's modulus decreased around 58\%. PHBV/FC 60/40 showed a decrease in flexural strength around $94 \%$ and Young's modulus 
decreased around $95 \%$. After 90 days of exposure to burial-soil test, it was possible to observe a continuing loss of mechanical properties for neat PHBV. On the other hand, both composites showed a slight increase in flexural strength and Young's modulus which agrees with the increasing crystallinity and better thermal resistance if compared to the samples with 60 days of exposure to burial-soil test.

Table 6 Average mechanical properties values and respective standarddeviations for neat PHBV, PHBV/CF 80/20 and PHBV/CF 60/40 before and after burial-soil test

\begin{tabular}{|c|c|c|c|}
\hline \multicolumn{4}{|l|}{ PHBV } \\
\hline Exposition time & $\begin{array}{l}\text { Flexural } \\
\text { strength } \\
\text { (Mpa) }\end{array}$ & $\begin{array}{l}\text { Elongation at } \\
\text { the break (\%) }\end{array}$ & $\begin{array}{l}\text { Young's } \\
\text { Modulus } \\
\text { (GPa) }\end{array}$ \\
\hline Before exposition & $27.0 \pm 1.0$ & $4.1 \pm 0.3$ & $1.27 \pm 0.13$ \\
\hline After 30 days & $27.0 \pm 2.0$ & $4.1 \pm 0.3$ & $1.97 \pm 0.17$ \\
\hline After 60 days & $24.7 \pm 2.2$ & $1.9 \pm 0.3$ & $2.77 \pm 0.34$ \\
\hline After 90 days & $21.5 \pm 3.9$ & $4.6 \pm 0,5$ & $0.94 \pm 0.17$ \\
\hline \multicolumn{4}{|l|}{$\mathrm{PHBV} / \mathrm{CF} 80 / 20$} \\
\hline Exposition time & $\begin{array}{l}\text { Flexural } \\
\text { strength } \\
\text { (Mpa) }\end{array}$ & $\begin{array}{l}\text { Elongation at } \\
\text { the break (\%) }\end{array}$ & $\begin{array}{l}\text { Young's } \\
\text { Modulus } \\
\text { (GPa) }\end{array}$ \\
\hline Before exposition & $27.0 \pm 1.0$ & $4.1 \pm 0.3$ & $1.96 \pm 0.17$ \\
\hline After 30 days & $21.0 \pm 0.7$ & $4.0 \pm 0.4$ & $1.71 \pm 0.17$ \\
\hline After 60 days & $13.22 \pm 1.3$ & $3.7 \pm 0.4$ & $0.82 \pm 0.1$ \\
\hline After 90 days & $16.1 \pm 1.6$ & $3.2 \pm 07$ & $0.90 \pm 0.18$ \\
\hline \multicolumn{4}{|l|}{$\mathrm{PHBV} / \mathrm{CF} 60 / 40$} \\
\hline Exposition time & $\begin{array}{l}\text { Flexural } \\
\text { strength } \\
\text { (Mpa) }\end{array}$ & $\begin{array}{l}\text { Elongation at } \\
\text { the break (\%) }\end{array}$ & $\begin{array}{l}\text { Young's } \\
\text { Modulus } \\
\text { (GPa) }\end{array}$ \\
\hline Before exposition & $29.0 \pm 2.2$ & $1.9 \pm 0.3$ & $2.77 \pm 0.34$ \\
\hline After 30 days & $10.5 \pm 4.0$ & $1.8 \pm 0.6$ & $1.50 \pm 0.43$ \\
\hline After 60 days & $1.7 \pm 0.5$ & $3.5 \pm 1.0$ & $0.13 \pm 0.017$ \\
\hline After 90 days & $4.8 \pm 2.8$ & $2.3 \pm 0.8$ & $0.63 \pm 0.18$ \\
\hline
\end{tabular}

SEM for neat PHBV and composites after burial-soil test: Since there were not large variations in thermal and mechanical properties for the neat PHBV, changes on surface morphology of the samples were evaluated over the time of exposure to burial-soil test. Figures 10 illustrate SEM micrographs of neat PHBV for different exposure times to burial-soil tests. According to Figure 11 \& Figure 12, after 60 days of exposure it is possible to observe pits and hemispherical cavities, and after 90 days it is also possible to observe large surface roughness and grooves, as showed in Figure 11 \& Figure 12 Shah and co-authors also observed cavities, pits and surface roughness on PHBV exposed to the action of microorganisms. ${ }^{13}$ Formation of hemispherical cavities on the surface may be caused by bacterial colonization. The formation of an interconnected network of grooves is due to the colonization of actonimicetas and fungi. The grooves around fungal hyphae indicate that they were formed as a result of degradation by the enzyme PHBV depolymerases excreted by fungal hyphae..$^{14}$ Analyzing SEM micrographs illustrated in Figure 11 it is possible to observe these networks of grooves on the surface of PHBV samples, as well as several irregular cavities, which indicates that the colonization of fungi and bacteria present on the surface of the samples contributed to their degradation. SEM results indicate that the neat PHBV suffered surface degradation process, even without showing large losses of thermal and mechanical properties. A longer exposure time to burial-soil test for neat PHBV samples is necessary for the development of colonies of microorganisms in such a way that can promote the degradation levels observed in composites PHBV/ $\mathrm{CF}$.
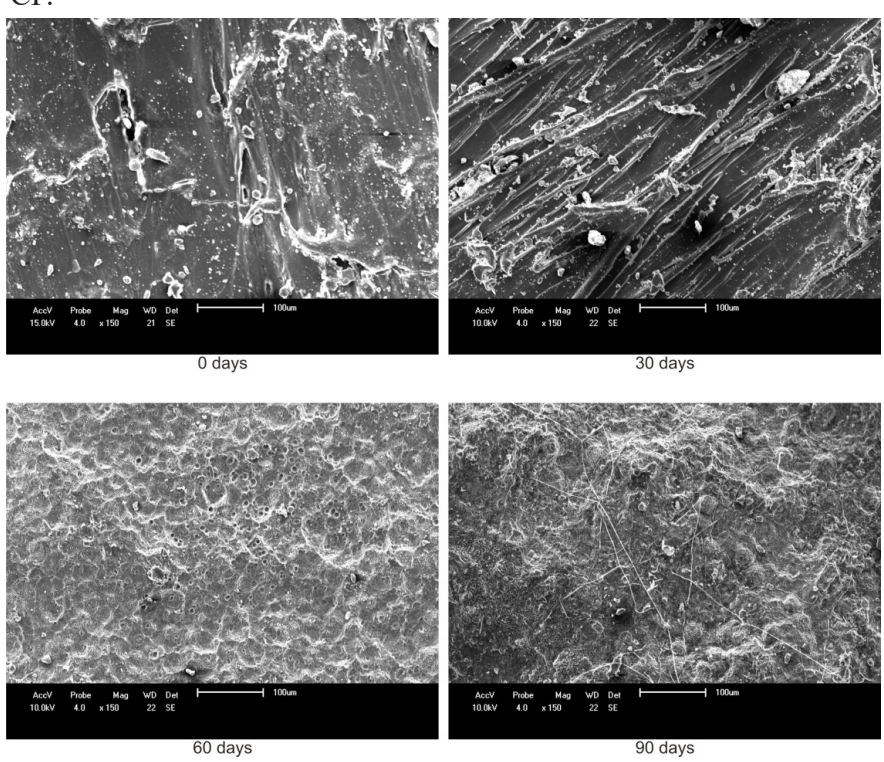

Figure 10 SEM micrographs for neat PHBV with different exposure times to burial-soil test.
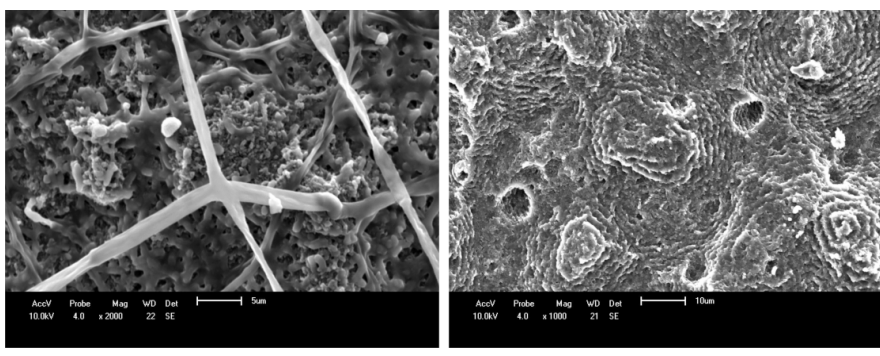

Figure II SEM micrographs for neat PHBV after 60 days of exposure time to burial-soil test.
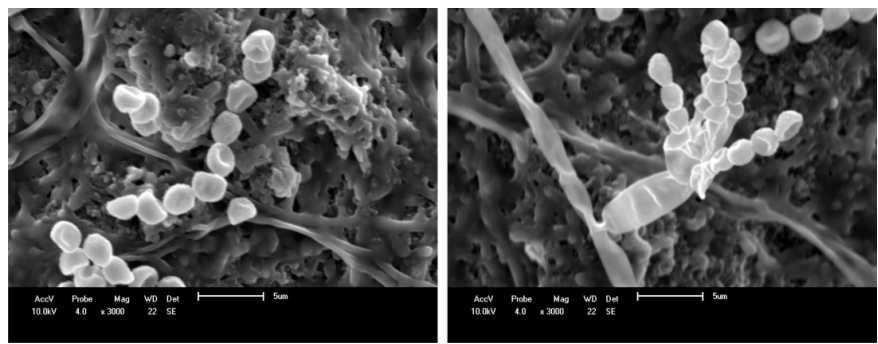

Figure 12 SEM micrographs for neat PHBV after 90 days of exposure time to burial-soil test.

\section{Conclusions}

Results showed that the addition of cellulose fibers improves the mechanical properties of PHBV with no appreciable changes to its thermal properties. Regarding to biodegradation, results showed that all samples exposed to burial-soil test experienced a decreasing on their thermal and mechanical properties. Composites with $40 \mathrm{wt} \%$ 
cellulose fibers showed higher degradation with exposure to burialsoil test probably due to the cellulose susceptibility to moisture and, consequently a microbial degradation. The degradation of cellulose facilitates the access of microorganisms to PHBV. Thus, after use, the composites can have their degradation process favored.

\section{Acknowledgements}

Authors would like to acknowledge the companies Cambara S.A. and PHB Industrial S.A. for donating the materials used in this research. The authors would like to express their gratitude to CAPESPROSUP and the support of the National Council for Scientific and Technological Development (CNPQ) for the Productivity Research PQ2 scholarship.

\section{Conflicts of interest}

The authors declare that there is no conflict of interest.

\section{References}

1. Corre Y, Bruzaud S, Audic J, et al. Morphology and functional properties of commercial polyhydroxyalkanoates: A comprehensive review and comparative study. Polymer Testing. 2012;31:226-235.

2. Weng Y, Wang Y, Wang XL, et al. Biodegradation behavior of PHBV films in a pilot-scale composting condition. Polymer Testing. 2010;29:579587.

3. Chen W, Tong TW. PHBV microspheres as neural tissue engineering scaffold support neuronal cell growth axon-dendrite polarization. Acta Biomaterialia. 2012;8:540-548.

4. Singh S, Mohanty AK, Sugie T, et al. Renewable resource based biocomposites from natural fiber and polyhydroxybutyrate-co-valerate (PHBV) bioplastic. Composites: Part A. 2008;39:875-886.
5. Singh S, Mohanty AK, Misra M. Hybrid biocomposite from talc, Wood fiber and bioplastic: Fabrication and characterization. Composites: Part A. 2010;41:304-312.

6. Netravali AN. Advanced green composites: New directions. Materials Today: Proceedings. 2019;8:832-838.

7. Singh S, Mohanty AK. Wood fiber reinforced bacterial bioplastic composites: Fabrication and performance evaluation. Composites Science and Technology. 2007;67:1753-1763.

8. Zhijiang C, Chengwei H, Guang Y. Poly (3-hydroxubutyrate-co4-hydroxubutyrate)/bacterial cellulose composite porous scaffold: Preparation, characterization and biocompatibility evaluation. Carbohydrate Polymers. 2012;87:1073-1080.

9. Espert A, Vilaplana F, Karlsson S. Comparison of water absorption in natural cellulosic fibres from wood and one-year crops in polypropylene composites and its influence on their mechanical properties. Composites: Part A. 2004;5(11):1267-1276.

10. Correa MCS, Rezende ML, Rosa DS, et al. Surface composition and morphology of poly (3-hydroxybutyrate) exposed to biodegradation. Polymer Testing. 2008;27:447-452.

11. Refaat AA. Biofuels from Waste Materials. Comprehensive Renewable Energy. 2012;5:217-261.

12. Goldstein S Wood. Formation and Properties- Chemical Properties of Wood. Encyclopedia of Forest Sciences. 2004:1835-1839.

13. Shah AA, Hasan F, Hameed A. Degradation of poly (3-hydroxybutyratco-hydroxyvalerate) by a newly isolated Actinomatura sp AF-555 from soil. International Biodeterioration \& Biodegradation. 2010;64:281285 .

14. Sang BI, Hori K, Tanji Y, et al. A kinetic analysis of the fungal degradation process of poly(3-hydroxybutyrate-co-3-hydroxyvalerate) in soil. Biochemical Engineering Journal. 2001;9(3):175-184. 